Samadi, H; Ayatizadeh, F; Axt, G; Machado, S (2021). Comparison between mindfulness and cognitive-behavioral psychological interventions on the reduction of pre-competitive stress of elite shooters: a follow-up of 2 months. Cuadernos de Psicología del Deporte, 21(1), 192-203

\title{
Comparison between mindfulness and cognitive-behavioral psychological interventions on the reduction of pre-competitive stress of elite shooters: a follow-up of 2 months
}

\author{
Comparación entre la atención plena y las intervenciones psicológicas \\ cognitivo-conductuales sobre la reducción del estrés precompetitivo de los \\ tiradores de élite: un seguimiento de 2 meses
}

\section{Comparação entre mindfulness e intervenções psicológicas cognitivo- comportamentais na redução do estresse pré-competitivo de atiradores de elite: um acompanhamento de 2 meses}

\author{
Hussein Samadi ${ }^{1}$, Faranahz Ayatizadeh ${ }^{1}$, Glaciane Axt ${ }^{2}$, Sergio Machado ${ }^{2,3}$ \\ ${ }^{1}$ Yazd university, Iran; ${ }^{2}$ Laboratory of Physical Activity Neuroscience, Physical Activity Sciences \\ Postgraduate Program, Niterói, Brazil; ${ }^{3}$ Laboratory of Physical Activity Neuroscience, Neurodiversity \\ Institute, Queimados, Brazil.
}

\begin{abstract}
Objectives: To compare the effectiveness of training cognitive-behavioral strategies and interventions based on mindfulness in the competitive stress of snipers (ie, salivary cortisol level) with two-month follow-up. Methods: Twenty-four young male professional snipers with a history of shooting for at least 3 years were randomly divided into three groups: cognitive-behavioral intervention $(n=8)$, intervention based on mindfulness $(n=8)$ and group of control $(n=8)$. Participants in the experimental groups participated in six training sessions over six weeks $(75-90$ minutes each session). The concentration of salivary cortisol was measured at rest, pre and post-test and follow-up. Results: ANOVA with repeated measures showed a main effect for the group $(\mathrm{F} 2.21=3.787$, sig $=0.039)$ and stage $(\mathrm{F} 3.21=52.529, \mathrm{sig}=0.001)$ and also the interactive effect between the groups in the stage $(\mathrm{F} 6,42=3.700$, sig $=$ 0.005). Repeated measures ANOVA showed that the cognitive-behavioral intervention at the level of salivary cortisol had an effect on the post-test, while the mindfulness intervention had positive effects on the post-test and follow-up times. There was no significant difference between the mindfulness and cognitive-behavioral groups in the post-test. In addition, the results of the follow-up time showed that there was a significant difference only between mindfulness and the control group. Practical Applications: The results indicate that the practice of psychological skills, especially mindfulness, can be used to reduce pre-competition stress.
\end{abstract}

Keywords: cognitive-behavioral strategy training, mindfulness-based intervention, salivary cortisol, pre-competitive stress. 


\section{Pre-competitive stress in elite shooters}

\section{RESUMEN}

Objetivos: Comparar la efectividad del entrenamiento de estrategias e intervenciones cognitivo-conductuales basadas en la atención plena en el estrés competitivo de los francotiradores (es decir, nivel de cortisol salival) con un seguimiento de dos meses. Métodos: Veinticuatro francotiradores profesionales varones jóvenes con antecedentes de disparos durante al menos 3 años se dividieron aleatoriamente en tres grupos: intervención cognitivo-conductual $(n=8)$, intervención basada en la atención plena $(n=8)$ y grupo de control $(n=8)$. Los participantes de los grupos experimentales participaron en seis sesiones de formación durante seis semanas (75-90 minutos cada sesión). La concentración de cortisol en saliva se midió en reposo, antes y después de la prueba y el seguimiento. Resultados: ANOVA con medidas repetidas mostró un efecto principal para el grupo ( $\mathrm{F} 2.21=3.787$, sig=0.039) y etapa $(\mathrm{F} 3.21=52.529, \mathrm{sig}=0.001)$ y también el efecto interactivo entre los grupos en la etapa $(\mathrm{F} 6,42=3.700$, sig $=0.005)$. El ANOVA de medidas repetidas mostró que la intervención cognitivo-conductual a nivel de cortisol salival tuvo un efecto en el postest, mientras que la intervención de mindfulness tuvo efectos positivos en el postest y los tiempos de seguimiento. No hubo diferencias significativas entre los grupos de atención plena y cognitivo-conductual en la prueba posterior. Además, los resultados del tiempo de seguimiento mostraron que hubo una diferencia significativa solo entre la atención plena y el grupo de control. Aplicaciones prácticas: Los resultados indican que la práctica de habilidades psicológicas, especialmente la atención plena, se puede utilizar para reducir el estrés previo a la competencia.

Palabras clave: entrenamiento en estrategias cognitivo-conductuales, intervención basada en mindfulness, cortisol salival, estrés precompetitivo.

\section{RESUMO}

Objetivos: Comparar a eficácia do treinamento de estratégias cognitivo-comportamentais e intervenções baseadas na atenção plena no estresse competitivo de atiradores (ou seja, nível de cortisol salivar) com acompanhamento de dois meses. Métodos: Vinte e quatro jovens atiradores profissionais do sexo masculino com histórico de tiro por pelo menos 3 anos foram divididos aleatoriamente em três grupos: intervenção cognitivo-comportamental $(n=8)$, intervenção baseada em atenção plena $(n=8)$ e grupo de controle $(n=8)$. Os participantes dos grupos experimentais participaram de seis sessões de treinamento durante seis semanas (75-90 minutos cada sessão). A concentração de cortisol salivar foi medida nos tempos de repouso, pré e pós-teste e acompanhamento. Resultados: ANOVA com medidas repetidas mostrou um efeito principal para o grupo $(\mathrm{F} 2,21=3,787$, sig $=0,039)$ e estágio $(\mathrm{F} 3,21=52,529$, sig $=0,001)$ e também o efeito interativo entre os grupos no estágio $(\mathrm{F} 6,42=3,700, \mathrm{sig}=0,005)$. ANOVA com medidas repetidas mostrou que a intervenção cognitivo-comportamental no nível de cortisol salivar teve efeito no pós-teste, enquanto a intervenção de atenção plena teve efeitos positivos nos tempos de pós-teste e acompanhamento. Não houve diferença significativa entre os grupos mindfulness e cognitivo-comportamental no pós-teste. Além disso, os resultados do tempo de acompanhamento mostraram que houve diferença significativa apenas entre a atenção plena e o grupo de controle. Aplicações Práticas: Os resultados indicam que a prática de habilidades psicológicas, especialmente a atenção plena, pode ser usada para reduzir o estresse pré-competição.

Palavras-chave: treinamento de estratégias cognitivo-comportamentais, intervenção baseada em mindfulness, cortisol salivar, estresse pré-competitivo.

\section{INTRODUCTION}

Undoubtedly, at any level and in each discipline, athletes may face many pressures from competition and performance (Humara, 1999). One of the most phenomena that lead to acute stress is the participation in the sporting events for success
(Aranzana Juarros et al., 2018). Stress, in particular, is by far the most studied phenomenon in sport psychology (Coelho et al., 2014). Researchers say that stress is a bio-hormonal response to the socialpsychological environment and internal and external stimuli and being in a variety of competitive 


\section{Sadimi, H., Ayatizadeh, F., Axt, G., Machado, S.}

conditions, in addition to creating pressure in the psychological dimension, changes the physiological response of athletes and depending on its severity and the athlete's perception, it can have detrimental effects on the psychological and physical aspects of the organism (Filaire et al., 2014; Arruda et al., 2017; Capranica et al., 2017). Regarding psychological stress, the researchers believe that the reason for this is an increase in the activity of the limbic system, especially the amygdale and the hippocampus region, which sends signals to the posterior medial part of the hypothalamus (Glesson, 2007; Stojanovich, 2010; Webster Marketon \& Glaser, 2008). Therefore, the final product of the hypothalamus-pituitary-adrenal axis (HPA) is cortisol, which is activated when faced with psychological and physical stress conditions, and the dangerous physiological complications caused by these changes may be very worrying (Budde et al., 2018; Hellhammer et al., 2009). Cortisol is a reliable indicator of HPA axis functions and when a competitive demand is perceived, the HPA axis is activated resulting in an increase in cortisol (Coelho et al., 2014).

Despite extensive research on competition stress, our understanding of this phenomenon is ambiguous. Due to the importance of the subject, in recent years, researchers have tried to provide effective ground for athletes to deal with stress in different sports by conducting extensive research on the causes of stress and ways to deal with it. Reduce their emotional and psychological problems at sporting events (Olmedilla et al., 2019; McCormick et al., 2017). During the last 30 years, the psychological techniques predominately used to enhance athletic performance and self-control of internal states have stemmed mainly from psychological skills training (PST), which is influenced mostly by cognitivebehavioral theories (John et al., 2010).

In fact, cognitive-behavioral intervention (CBI) is based on the assumption that negative internal states, such as negative thoughts, emotions and negative physical sensations have prevented the desired performance and they must be stopped, controlled or decreased through positive thoughts and self-confidence. The role of cognitive-behavioral strategies for controlling emotions, facilitating adaptation to competitive pressure, and enhancing performance among athletes have been confirmed in amateur, academic, professional and Olympic (Humara, 1999).
For example, Davis et al. (2009) investigated the efficacy of cognitive-behavioral methods on reducing the mood and salivary cortisol in a 30-yearold Olympic athlete, reducing the distress and levels of salivary cortisol following the program. John et al (2010) found the effect of music therapy on HPA-Axis by decreasing the level of Salivary Cortisol and reducing pre-competition stress on shooting performance. Coelho et al. (2014) in a research study in volleyball players showed that the mental training program had a significant reduction in salivary cortisol concentration and stress. Slimani et al. (2017) investigated the effectiveness of psychological physical interventions on the physiological and hormonal changes (cortisol) in elite athletes and reported physiological compatibility and cortisol levels. However, some studies, such as Olmadilla et al. (2019) did not observe a significant difference in the stress control factor of adolescent football players following 8-week behavioral cognitive program. In the study of Wegner et al. (2014) the increase in cortisol levels was found after psychosocial stress, not exercise with different intensities in school classes.

Despite the positive results of CBI, recent literature emerged from among the collections of subdisciplines of the psychology has been questioned this assumption that negative internal experiences always lead to negative behavioral consequences. Some scientific studies suggest that suppressing thoughts and controlling negative thinking patterns can increase unwanted cognitive activities (Gardner \& Moore, 2006; Gardner \& Moore, 2007). So nowadays, we are faced with the third generation of new and integrated therapies that can be called generalized acceptancebased models.

Recently mindfulness-based interventions (MBI) are used as the new interventions to treat and prevent many psychological disorders and problems. Mindfulness means paying attention at the present, in a specific, purposeful and non-judgment manner. Mindfulness allows an individual to reviewall internal and external in formational input and to be able to experience the changed relationship toward normal reactions. The goal of the MBI is to reduce suffering by developing equanimity in mind and body, as well as gaining insight in to mental and physical conditions that inhibit an individual's capacity to respond proactively and effectively to daily events (ScottHamilton et al., 2016; Mehrsafar et al., 2019). 


\section{Pre-competitive stress in elite shooters}

This approach is clearly both in terms of both theoretical and interventional strategies, different from the traditional practice of psychological skills approach that dominates applied sport psychology (Gardner \& Moore, 2006; Gardner \& Moore, 2007). The effectiveness of MBI on phychological variables such as flow (Meggs \& Chen, 2019; Chen \& Meggs, 2019), anxiety (Scott-Hamilton et al., 2016; Chen \& Meggs, 2020), worries and task-irrelevant thoughts. However, only a few studies have examined the effect of MBI on salivary cortisol changes due to competitive stress (Thompson et al., 2011; Pascoe et al., 2017). For example, John et al. (2011) found a decrease in salivary cortisol levels after a mindfulness awareness program and also in the follow-up stage. MacDonald and Minahan (2018) showed reduced salivary cortisol levels in wheelchair basketball players following their eight-week mindfulness program. Also, MehrSafar et al. (2019) showed the effectiveness of mindfulness exercises on reducing psychological and physiological responses to competitive stress in elite athletes. Also these changes remained stable up to 2-month followup.

The studies of the effectiveness of psychological interventions on factors such as stress have found different results. Because of pressure of competition threatens the athletes' psychophysiological health, the researches must conduct and find the suitable and consistent intervention to control the negative effects of stress-related behavior (Mehrsafar et al., 2019). The most of researches have done in the field of psychological dimension of stress, and investigations in the strategies of reduction and coping with physiological indicators of stress are in the early stages. Although psychology studies have often focused on the brain alone, recently investigations are about the role of hormones on the brain function and also the use of physiological and biochemical indicators (e.g., blood and salivary cortisol) to understand the effects of stress (Davis et al., 2019). Given the role of stress in elevating cortisol, athletes have to use different psychological interventions to decrease the harmful effects of stress on the immune system.

In addition, despite the need to examine the long-term effects of interventions (efficacy), few psychological studies have followed up their training programs and reported only their immediate effects (effectiveness). In fact, effectiveness considers immediate effects after the program, while the efficiency associated with long-term effects is related to the consequences of the effectiveness (Rumbold et al., 2012). There has been no research on the comparison of the effectiveness of CBI and MBI on the concentration of salivary cortisol; new interventions in the field of exercise seem necessaries. Therefore, the objective of this study is to compare the effectiveness of cognitive-behavioral strategies training and mindfulness based-interventions on shooters competitive stress (i.e., level of salivary cortisol) with two-months follow-up. Our hypothesis is that CBI and MBI will have lower levels of cortisol concentration in comparison to control group in post test, and MBI lower levels of cortisol concentration in comparison to CBI and control group in follow-up.

\section{MATERIAL AND METHOD}

Sample

The statistical population of the study consisted of all male (gun and pistol) shooters with age range of 17-22 years old who were volunteered to participate in the research after obtaining a formal license from the Yazd province youth and sports department. All athletes have had at least three years of regular activity in the field of shooting and experience in provincial and national competitions, and have been physically and psychologically in perfect health.

\section{Training Protocol}

The psychological training program was conducted under the supervision of a researcher and with the help of an experienced clinical psychologist. Participants in the experimental groups participated in six training sessions during six weeks (75-90 minutes each session). The cognitive-behavioral intervention program was similar to the included identifying stressful thoughts, avoiding and stopping negative thoughts, relaxation, mental training, visualization and imagery, positive self-talk, attention and concentration, and adjusting arousal, increase or decrease the level of activation and daily homework (Patrick \& Hrycaiko, 1998). The mindfulness intervention program includes raisin exercises, sitting meditation focusing on breathing, body scanning meditation, yoga practice, walking meditation and special exercise meditation (John et al., 2011; MacDonald \& Minahan, 2018; KabatZinn et al., 1992) and daily homework. 


\section{Sadimi, H., Ayatizadeh, F., Axt, G., Machado, S.}

It should be noted that at the end of each session, special worksheets were given to individuals to record homework and a message was sent in cyberspace to remind them about doing homework and recording activities. Subjects were asked to use and record the taught sessions of the sessions during the weekdays in their daily activities, and to participate in a group discussion at the beginning of the next session.

\section{Salivary Cortisol Measurement}

Cortisol measurement in research has been used as a stress marker. It is a simple, non-invasive and stress-free method for measuring the activity of the axis of HPA and is a classic biological index for measuring the degree of stress or tension (Hellhammer et al., 2009). Cortisol, the most important glucocorticoid, is synthesized by the adrenal cortex and can be assessed by salivary, urinary, and plasma testing. The advantage of the salivary cortisol measurement over plasma testing is because of an easier and a noninvasive assessment of cortisol. Salivary cortisol has been commonly used as a biomarker of psychological stress and related mental and/or physical diseases. It is also a reliable indicator of (HPA) axis functions (Wegner et al., 2014).

In this study, the salivary cortisol level was studied as a dependent variable and the salivary samples of athletes were performed four times: Before the first and second official match (pre-test and posttest), before the third official match (follow-up phase, two months after the post-test) and at rest time (one week after the first match). To measure the stress level was used Cortisol (German IBL cortisol kit, RE52611 model with sensitivity of $0.1 \mu \mathrm{g} / \mathrm{dl}$ ) with ELISA method. The researcher collected salivary samples of athletes for 10-15 minutes, before the start of the selected matches in the province (Because of the assurance of the importance of the match for athletes) to measure the level of salivary cortisol (this field was chosen because the level of the tournament, the opponent team and have not a different effect on the stress of athletes).

To measure cortisol, before the official match, athletes were asked to wash their mouths with half a glass of cold water and after keeping one to two minutes of salivary in their mouth; they took about 2$3 \mathrm{mg}$ of your unconventional salivary into the test tubes. The matches started at 11 a.m. and lasted about 75 minutes. Also, the measurement of cortisol levels was done during the rest because athletes did not experience any stress. After applying the desired intervention, the researcher again recollected salivary cortisol from athletes again 10-15 minutes before a formal match with similar sensitivity to the previous round. It should be noted that cortisol secretion follows the night rhythm and therefore, sampling time was the same at all stages and the effect of night-time rhythm was controlled on the secretion of hormones. At all stages of the experiment, the salivary samples collected were quickly frozen and transferred to the specialized laboratory as soon as possible. After collecting salivary samples, the specimens were frozen at $-20^{\circ} \mathrm{C}$ until laboratory tests. At the test day, the samples were first placed at room temperature to exit them from freeze mood. Then salivary specimens were centrifuged to dissolve the mucus. Concentration of cortisol was measured using transparent fluid in the tube. All salivary specimens were tested under the same environmental conditions (time, place and experimenter).

\section{Experimental procedures}

This is an experimental research using a preand post-test, follow-up design with control group. Thus, to select the research samples, the consent, psychological, physical forms and activity history was used in the research. According to the information obtained from the coaches and athletes, none of the participants had a history of attending psychological classes and this period was their first experience. After selecting the qualified individuals according to the information obtained from the questionnaire and explanation of the purpose of the present study, written consent and commitment form of participation in the class and test were taken. Twenty four participants were randomly assigned into three groups: cognitive-behavioral intervention $(n=8)$, mindfulness based intervention $(\mathrm{n}=8)$ and control group $(\mathrm{n}=8)$.

Statistical analysis

In this research, descriptive statistics were used to categorize information and presenting means and standard deviations and from inferential statistics for data analysis. The Shapiro-Wilk test was used to determine the normality of the data, and repeated measure ANOVA and one way ANOVA were used to compare the concentration of salivary cortisol in the control and experimental groups. In addition, Tukey's post-hoc test (LSD) was performed with the objective of multiple comparisons. In all tests, the confidence 


\section{Pre-competitive stress in elite shooters}

level was considered to be 0.05 . Data were analyzed by software SPSS version 20. In order to obtain the sample calculation, GPower version 3.1. was used.

\section{RESULTS}

The demographic characteristics of the two experimental and control groups are presented in Table 1.

Table 1 - The demographic characteristics of the two experimental and control groups.

\begin{tabular}{rrrr}
$\begin{array}{c}\text { Group } \\
\text { Variable }\end{array}$ & $\begin{array}{r}\text { MBI } \\
\text { group } \\
(\mathbf{N}=8)\end{array}$ & $\begin{array}{r}\text { CBI } \\
\text { group } \\
(\mathbf{N = 8})\end{array}$ & $\begin{array}{r}\text { Control } \\
\text { group } \\
(\mathbf{N = 8})\end{array}$ \\
\hline $\begin{array}{r}\text { Age } \\
(\text { year })\end{array}$ & $20 \pm 1.05$ & $19.4 \pm 1.71$ & $19 \pm 1.24$ \\
\hline $\begin{array}{r}\text { Height } \\
(\mathrm{cm})\end{array}$ & $174 \pm 2.49$ & $172 \pm 2.36$ & $175.2 \pm 2.82$ \\
\hline $\begin{array}{r}\text { Weight } \\
(\mathrm{kg})\end{array}$ & $64.2 \pm 1.68$ & $63.6 \pm 2.71$ & $62.7 \pm 1.88$ \\
\hline
\end{tabular}
according to the number of samples, Shapiro-Wilk test was used in all variables of the study, a significance level greater than 0.05 was obtained, which indicates the normality of data distribution. The results of cortisol analysis using the mixed analysis of variance with 3 (group) $* 4$ (stage) design showed the main effect for group $(\mathrm{F} 2,21=3.787$, sig $=0.039)$ and stage $(\mathrm{F} 3,21=52.529, \operatorname{sig}=0.001)$ and also the interactive effect between the groups in the stage $(\mathrm{F} 6,42=3.700$, $\operatorname{sig}=0.005)$ is significant. Due to the significance of the main effect for the group and the stages, in order to evaluate the differences between the groups, ANOVA test was used and also to evaluate the differences between the stages in each group (main effect for the stage), repeated measures analysis of variance test was used.

\section{Main effect for group}

The results showed that there was no significant difference between the groups in the resting stage $(\mathrm{F} 2,21=0.000$, sig $=1.000)$ and pre-test $(\mathrm{F} 2,21=0.470, \mathrm{sig}=0.631)$, but in the post-test stage $(\mathrm{F} 2,21=9.176$, sig $=0.001)$ and follow-up $(\mathrm{F} 2,21=$ 4.207 , sig $=0.028$ ) there was a significant difference, so that in the post-test stage, both groups CBI and MBI were significantly different from the control group ( $\mathrm{P}$ $=0.001)$, but the difference between MBI and CBI groups was not significant $(\mathrm{P}=0.931)$. Also, in the follow-up stage, only the MBI group was significantly different from the control group $(\mathrm{P}=0.01)$. However, there was no significant difference between the CBI and control groups $(\mathrm{P}=0.057)$ and the $\mathrm{MBI}$ and $\mathrm{CBI}$ groups $(\mathrm{P}=0.471)$.

\section{Main effect for stage}

The results of the study showed that there was a significant difference between the stages in the mindfulness group $(\mathrm{F} 3,5=9.314$, sig=0.019), so that the difference between the stages of rest - pre-test, pre-test-post-test was significant $(\mathrm{P}<0.05)$ and the only difference between post-test and follow-up is not significant $(\mathrm{P}=0.20)$. In the cognitive-behavioral group, the difference between the stages (F3,5=9.314, sig $=0.001)$ was significant, so that the difference between the stages of rest, pre-test and post-test was significant $(\mathrm{P}<0.05)$, and only the difference between the stages of pretest and follow up are not significant $(P=0.354)$. In the control group, the difference between the stages was significant $(F 3,5=23.922$, sig $=0.001)$, so that the difference between stages of resting and pre test $(\mathrm{P}=0.02)$ was significant and difference between the stages pre test - post test and post test - follow up $(\mathrm{P}>0.05)$ was not significant (See fig. 1).

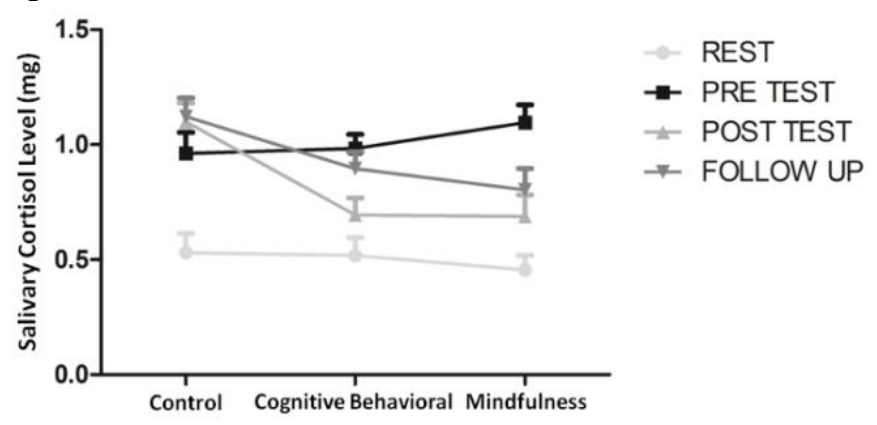

Figure 1. Cortisol changes in $\mathrm{CBI}$ and $\mathrm{MBI}$ and control groups at different stages.

\section{DISCUSSION}

Stressful conditions during competitions produces significant changes in physiological, psychological, and behavioral responses and provoke psychological disorders, that may negatively on the affect the athlete's performance (Brown \& Fletcher, 2017; Bennet \& Maynard, 2017). The present study compares the effectiveness of cognitive-behavioral intervention and mindfulness based intervention on the competitive level of shooters using a valid 


\section{Sadimi, H., Ayatizadeh, F., Axt, G., Machado, S.}

physiological index such as salivary cortisol. The findings showed that both methods of cognitivebehavioral strategies training and mindfulness-based intervention had a positive and significant effect on reducing the levels of salivary cortisol in the participants. Although there was no significant difference on salivary cortisol level in the resting and pre-test stages between groups, the salivary cortisol level of the cognitive-behavioral and mindfulness strategies group decreased after six weeks of training and this amount was maintained for the mindfulness group at a two-month follow-up stage. The results also show that there is a difference between the control and experimental groups at the salivary cortisol level in the post-test, but there is no significant difference between cognitive-behavioral strategies and mindfulness groups in the post-test and follow-up stages.

As mentioned, in addition to psychological reactions, the acute response to competitive stress also involves the activation of physiological systems including the activation of the autonomic nervoussystem (ANS) with the release of catecholamines and the HPA axis with the creation of cortisol (Hellhammer et al., 2009). The researchers agree that in addition to the effect of physical activity, the psychological arousal associated with competition also affects the HPA axis and increases the production and secretion of cortisol (Haneishi et al., 2007). Considering that the research participant did not have physical activity and pressure before the competition, a significant increase in cortisol before the competition in relation to rest can be attributed to the psychological pressures of the competition and its reduction after intervention as a result of $\mathrm{CBI}$ and $\mathrm{MBI}$ interventions.

The findings of the present study are consistent with the results of Coelho et al. (2014) and Eslimani et al. (2017) following a traditional psychological program, while inconsistent with the results of Olmedilla et al. (2019). They given the higher scores on psychological skills and performance appraisal of players, stated that subjects may have been able to improve stress management related to performance appraisal and the use of techniques and psychological resources. However, these differences between studies may be due to the nature of the intervention and the type of program, the location and duration of the program.

Also, in explaining these findings and according to studies that are consistent with the results of this study, psychological skills training based on the cognitive-behavioral model has been effective in reducing the negative physiological responses of competitive stress, in other words, CBI has probably been able to prevent negative thoughts and emotions, such as tension, and also cause a balance in the HPA axis, which will result in the prevention of high cortisol secretion.

In addition, the psychological skills training based on the cognitive-behavioral model approach helps the individual to recognize distorted thought patterns and dysfunctional and to adjust and correct irrational thoughts and belief systems. CBI in athletes emphasizes the usefulness of thoughts and cognitions that lead to positive emotions and moods in sport achievement. In other words, this method challenges the athlete's cognitive distortions and launches them with cognition that is effective and compatible with the sport (Murphy et al., 1993; Turner et al., 2014).

In this study, to evaluate the effectiveness of cognitive-behavioral approach, an intervention package were used including identifying stressful thoughts, avoiding and stopping negative thoughts, relaxation, mental training, visualization and imagery, positive self-talk, self-regulation and daily homework. Murphy y Jowdy (Sofian et al., 2009) stated that imagery and relaxation techniques are important elements of stress adjustment. Researchers believe that training traditional psychosocial skills, such as relaxation and imagery help athletes to control the autonomic nervous system and gain enough awareness of internal changes in the body and consequently, the self-regulation ability and, in addition, use them in difficult tought situations. Researchers also show that imaging enhances the ability to perceive cognitive and physical symptoms in any situation. According to the physiological dimension of attention-arousal theory, imaging can help the athlete to regulate the level of arousal and thus reduce muscle tension (Lau \& McMain, 2005). Also, Relaxation is a combination of cognitive-behavioral and psychological-physical interventions that create a balance between mental and emotional functions and reduce physical and psychological stress by creating appropriate physical and mental responses (Theodorakis et al., 2008). Relaxation exercises decrease the threshold for stimulating muscle synapses (Coelho et al., 2014) and can also reduce blood cortisol stress, heart rate, respiration rate and blood lactate (Coelho et al., 2014). 


\section{Pre-competitive stress in elite shooters}

Theodorakis et al. (2008) state that self-talk in addition to self-confidence, regulate cognitive and emotional reactions. Positive self-talk reduces negative thoughts and emotions through deliberate adjustment of speech content, and helps the athlete to be optimistic and positive (Mills et al., 2000). Walter et al. (2019) say that this method has a positive effect on psychological and behavioral factors and physiological variables. Positive self-talk also causes a balance between posterior and anterior hypothalamus and thus prevents undesirable effects from stress (Kasala et al., 2014). Also, in this research, the skill of stopping negative thoughts was taught during training and competition that athletes should stop negative thoughts with an image or sign, such as "red", or a saying like "stop" (Shapiro et al., 1998).

Most studies that use mental practice have shown an increase in the facilitation of symptom following their own schedule. In fact, mental practice based on the cognitive-behavioral model can significantly change the behavior and attitude of the athlete toward competition, which leads to selfregulation and self-confidence. Most researchers believe that multi-component interventions often have a positive effect on stress reduction and may help to optimize the various components of stress (Rumbold et al., 2012). Kasala et al. (2014) believe that this method can reduce the activity of the sympathetic nervous system, which in turn can reduce the activity of the AHP axis. In this study, a multi-component intervention package was used and reduction of stress was shown after 6 weeks of CBI.

One of the strengths of this study was to review the two-month follow-up phase, identify longterm effects, and evaluate the efficacy of the training program. The results showed that the effects of cognitive-behavioral training programs were eliminated in the follow-up phase. Also, the results showed no significant difference between the pre-test and follow-up stages. The study with taking he intervention package of traditional psychological skills was not found, but included the follow-up phase of the traditional psychological skills training program (music therapy). The results of present study did not match the findings of John et al. (2010) that showed positive effects of a relaxing music type after one week of their program on reducing salivary cortisol, while in the present study, the efficacy of this program was lost in the follow-up phase. Of course, it should be noted that the present study included a different psychological program consisting of multi-component intervention package with daily homework and a longterm follow-up phase. Perhaps the difference in the length of time the investigation of the follow-up phase led to this discrepancy. Anyway, this issue requires more research, and thus, there should be appropriate time interval to confirm the validation and efficacy of the programs, at least two months (Rumbold et al., 2012). John et al. (2010) have considered the limited follow-up time of one week, and therefore, determining the validity of their intervention requires future research.

Also, the results of the MBI group showed a significant difference in salivary cortisol levels following this program in the post-test phase and this effect was maintained at least until the two-month follow-up phase. In addition, there was a significant difference between the pre-test and follow-up stages. The results are consistent with the findings of John et al. (2011) and MehrSafar et al. (2019). This finding is consistent with studies that have shown the negative relationship between mindfulness and stress perception

Although cognitive-behavioral programs use control and emotion regulation strategies to help the athlete to control stress and negative emotions, the mindfulness practice program focuses on the nonjudgment acceptance of internal experiences, especially in the negative internal states. The mindfulness exercises program has ability to allow the passing of thoughts and reduces the occurrence and appearance of negative thoughts and leads to a reduction in the concern associated with assignment and thought unrelated to the task. These exercises lead to a state of mental relaxation, a reduction in tension and a reduction in symptoms and physical complaints. Although the main goal of the mindfulness is not relaxation, but observing the acceptance of internal negative events without any judgment about them can reduce stress and increase calmness. Mindfulness may be effective in helping to improve the relaxation response, improves attention self-regulation, and can serve as a strong behavioral coping tool which encourages participants to "see stress as a challenge, not a threat." It improves physiological relaxation and deep cognitive-behavioral changes, and can be an effective treatment for both physiological and cognitive aspects of stress, and teaches new ways of thinking about stressful situations and its management (Shapiro et al., 1998). Williams et al. (2001) have 


\section{Sadimi, H., Ayatizadeh, F., Axt, G., Machado, S.}

suggested that mindfulness can be an effective treatment for both physiological and cognitive aspects of stress, and teaches new ways of thinking about stressful situations and its management. Also, it has been shown that these exercises can reduce cortisol levels in stressful situations (Mehrsafar et al., 2019). Some evidence suggests that mindfulness exercises may be related to structural changes in the parts of the brain that deal with sensory, cognitive, and emotional processing, which reduces negative emotions by labeling negative emotional stimuli (Pepping et al., 2013; Creswell et al., 2007). In this study, the possibility of accepting negative experiences and a low attention to anxiety symptoms may help to reduce stress before the competition.

Another possible explanation for the findings of the present study is the individual creates an interaction between bodily, cognitive, and emotional processes by focusing on consciousness on his own body, which in turn causes him to accept or acknowledge the emotions resulting from events and to return to the balance after experiencing negative emotions. MBI allows the athlete to train mindfulness techniques while they are experiencing sensations (e.g. nervousness) and thoughts (e.g. subjective distress). It is assumed that the athlete is capable to observe naturally occurring competitions nonjudgmentally and non-reactively thereby increasing performance. Mindfulness permits athletes to be able to regulate thoughts and emotions (related to challenges and abilities) to enter awareness and act with awareness in competitive situations. This state may prevent self-critical thoughts and reflect true reality (Mehrsafar et al., 2019). It is also possible that MBI supports athletes to have an open and nonjudgmental approach to thoughts and feelings, which prevents athletes from being involved in unpleasant judgmental thoughts about the self (Scott-Hamilton et al., 2016; Pepping et al., 2013). MBI helps athletes to face challenges and stressors by providing a selfregulatory process incompetition. By gaining the ability to reappraise com-petitive challenges, athletes should be enabled to simultaneously evaluate psychological re-activity and regulate their physiological arousal response (Mehrsafar et al., 2019). It seems that the athletes in the present study, by directing their attention and awareness of the unpleasant experiences they have had and accepting these experiences without any judgment towards positive, pleasant and favorite events, have created an acceptable and acceptable mental state that this has led to a reduction in stress.

The findings are similar to the results of Pascoe et al. (2017) and Mehrsafar et al. (2019) about the positive effects of mindfulness program on reducing salivary cortisol levels in the follow-up phase. The results of Pascoe et al. (2017) showed a decrease in cortisol concentrations in the post-test phase and this reduction was maintained in the twomonth follow-up phase, although the follow-up time in the two studies was different. In the present study, although the participants had a history of shooting for three years, but had no history of participation in psychological classes, and perhaps this is why the training program on CBI and MBI in reducing level of cortisol. However, comparison of groups shows that although there is a difference between the experimental and control groups in the post-test, there was no significant difference between $\mathrm{CBI}$ and $\mathrm{MBI}$ in post-test and follow-up stages. So both strategies can be used as a means for reducing stress.

\section{PRACTICAL APPLICATIONS}

In general, the presence of psychological unknowns in some areas, especially athletic performance, instructors and physical education specialists are required to work more closely with their athletes in order to correct planning for them. By studying several researches on the effect of psychological skills on stress, we conclude that there are contradictory results in the investigated factors. Therefore, research to find the best way to reach the ultimate goal of an athlete, which is increasing exercise performance, is needed. Considering that the present study is one of the few studies on the effect of traditional psychological and mindfulness programs on salivary cortisol levels, future research requires researchers to design effective stress-related interventions and consider their efficacy in other sports.

\section{REFERENCES}

1. Humara, M. (1999). The Relationship Between Anxiety and Performance: A CognitiveBehavioral Perspective. Athletic insight: The Online Journal of Sport Psychology, 1(2), 1-14.

2. Aranzana Juarros, M., Salguero del Valle, A., Molinero González, O., Rosado, A. F. B., \& Márquez Rosa, S. (2018). Relación de la carga interna de 


\section{Pre-competitive stress in elite shooters}

entrenamiento, optimismo y resiliencia con los niveles de estrés-recuperación en nadadores. Cuadernos de Psicología del Deporte, 18(1), 43-54.

3. Coelho, R. W., Kuczynski, K. M., Paes, M. J., Greboggy, D., Santos, P. B., \& Rosa, P.D., \& Stefanello, J. F. (2014). Effect of a mental training program on salivary cortisol in volleyball players. Journal of Exercise Physiology, 17(3), 46-57.

4. Filaire, E., Le Scanff, C., Duché, P., \& Lac, G. (1999). The relationship between salivary adrenocortical hormones changes and personality in elite female athletes during handball and volleyball competition. Research Quarterly for Exercise and Sport, 70(3):297-302. $\frac{10.1080 / 02701367.1999 .10608048}{5.04}$

5. Arruda, A. F., Aoki, M. S., Paludo, A. C., \& Moreira, A. (2017). Salivary steroid response and competitive anxiety in elite basketball players: Effect of opponent level. Physiology \& Behavior, 177, 291296. 10.1016/j.physbeh.2017.05.017

6. Capranica, L., Condello, G., Tornello, F., Iona, T., Chiodo, S., Valenzano, A., Cibelli, G. (2017). Salivary alpha-amylase, salivary cortisol, and anxiety during a youth taekwondo championship: An observational study. Medicine, 96(28), 1-6. 10.1097/MD.0000000000007272

7. Gleeson, M. (2007). "Immune function in sport and exercise". Journal of Applied Physiology, 103(6), 693-99. 10.1152/japplphysiol.00008.2007

8. Stojanovich, L. (2010). "Stress and autoimmunity. Autoimmunity reviews, 9(2), 271-276. 10.1016/j.autrev.2009.11.014

9. Webster Marketon, J. I., \& Glaser, R. (2008). "Stress hormones and immune function". Cellular immunology, 252(6), 16-26.

10. Budde, H., Velasques, B., Ribeiro, P., Machado, S., Emeljanovas, A., Kamandulis, S., Skurvydas, A., \& Wegner M. (2018). Does intensity or youth affect the neurobiological effect of exercise on major depressive disorder? Neurosci Biobehav Rev, 84, 492-4. 10.1016/j.autrev.2015.09.004

11. Hellhammer, D. H., Wüst, S., \& Kudielka, B. M. (2009). Salivary cortisol as a biomarker in stress research. Psychoneuroendocrinology, 34(2), 163-71. 10.1016/j.psyneuen.2008.10.026

12. McCormick, A., Meijen, C., Anstiss, P. A., \& Jones, H. S. (2017). Self-regulation in endurance sports: theory, research and practice. Int Rev Sport Exerc Psychol, 12, 235-64. $\underline{10.1080 / 1750984 X .2018 .1469161}$
13. John, S., Verma, S. K., \& Khanna, G. L. (2010). The effect of music therapy on salivary cortisol as a reliable marker of pre competition stress in shooting performance. Journal of Exercise Science and Physiotherapy, 6(2), 70-77.

14. Davis, H., Baron, D., \& Gillson, G. (2009). Salivary cortisol and mood reductions in an olympic athlete using cognitive behavioral methods. Handbook of Sports Psychology.

15. Eslimani, M., Taylor, L., Baker, J. S., Elleuch, A., Ayedi, F. M., Chamari, K., \& Chéour, F. (2017). Effects of mental training on muscular force, hormonal and physiological changes in kickboxers. J Sports Med Phys Fitness, 57(7), 1069-1079. 10.23736/S0022-4707.16.06421-5

16. Olmedilla, A., Moreno-Fernández, I. M., Gómez-Espejo, V., Robles-Palazón, F. J., Verdú, I., \& Ortega, E. (2019). Intervention Program to Control Stress in Youth Soccer Players. Frontiers in Psychology, 10, 1-8. 10.3389/fpsyg.2019.02260

17. Wegner, M., Müller-Alcazar, A., Jäger, A., Machado, S., Budde, H. (2014). Psychosocial stress but not exercise increases cortisol and reduces state anxiety levels in school classes - Results from a stressor applicable in large group settings. CNS Neurol Disord Drug Targets, 13, 1015-1020. 10.2174/1871527313666140612103425

18. Gardner, F. L., \& Moore, Z. E. (2006). Clinical sport psychology. Champaign, IL: Human Kinetics.

19. Gardner, F. L., \& Moore, Z. E. (2007). The psychology of enhancing human performance: The mindfulness-acceptance-commitment

(MAC) approach. New York: Springer Publishing Company. 20. Scott-Hamilton, J., Schutte, N. S., \& Brown, R. F. (2016). Effects of a mindfulness intervention on sports-anxiety, pessimism, and flow in competitive cyclists. Applied Psychology Health and Well-Being, 8(1):85-103. 10.1111/aphw.12063

21. Mehrsafar, A. H., Strahler, J., Gazerani, P., Khabiri, M., Sánchez, J. C. J., Moosakhani, A., \& Zadeh, A. M. (2019). The effects of mindfulness training on competition-induced anxiety and salivary stress markers in elite Wushu athletes: A pilot study. Physiology \& Behavior, 210, 112655-64 10.1016/j.physbeh.2019.112655

22. Meggs, J., \& Chen, M. A. (2019). Competitive Performance Effects of Psychological Skill Training for Youth Swimmers. Perceptual and Motor Skills, 126(5), 886-903. 10.1177/0031512519852533 


\section{Sadimi, H., Ayatizadeh, F., Axt, G., Machado, S.}

23. Chen, M. A., \& Meggs, J. (2020). The effects of Mindful Sport Performance Enhancement (MSPE) training on mindfulness, and flow in national competitive swimmers. Journal of Human Sport and Exercise, in press. 10.14198/jhse.2021.163.04

24. Thompson, R. W., Kaufman, K. A., De Petrillo, L. A., Glass, C. R., Arnkoff, D. B. (2011). One year follow-up of mindful sport performance enhancement (MSPE) with archers, golfers, and runners. Journal of Clinical Sport Psychology, 5(2), 99-116. 10.1123/jcsp.5.2.99

25. Pascoe, M. C., Thompson, D. R., Jenkins, Z. M., \& Ski, C. F. (2017). Mindfulness mediates the physiological markers of stress: systematic review and meta-analysis. Journal of Psychiatric Research, 95, 156-78. 10.1016/j.jpsychires.2017.08.004

26. John, S., Kumar, V. S., \& Lal, K. G. (2011). The effect of mindfulness meditation on HPA axis in pre-competition stress in sport performance of elite shooters. National Journal of Integrated Research in Medicine, 2(3), 15-21.

27. MacDonald, L. A., \& Minahan, C. L. (2018). Mindfulness training attenuates the increase in salivary cortisol concentration associated with competition in highly trained wheelchair-basketball players. Journal of Sports Sciences, 36(4), 378-83. 10.1080/02640414.2017.1308001

28. Rumbold, J., Fletcher, D., \& Daniels, K. (2012). A systematic review of stress management interventions with sport performers. Sport, Exercise, and Performance Psychology, 1 (3), 173-193. 10.1037/a0026628

29. Patrick, T. D., \& Hrycaiko, D. W. (1998). Effects of a mental training package on an endurance performance. The Sport Psychologist, 12, 283-299.

30. KabatZinn, J., Massion, A., Kristeller, J., Peterson, L. G., Fletcher, K. E., Pbert, L., Lenderking, W. R., \& Santorelli, S. (1992). Effectiveness of a meditation-based stress reduction program. Am J Psychiatry, 149(7), 936-943. 10.1176/ajp.149.7.936

31. Bennett, J., \& Maynard, I. (2017). Performance blocks in sport: recommendations for treatment and implications for sport psychology practitioners. J. Sport Psychol in Action, 8, 60-68. 10.1080/21520704.2016.1227414

32. Brown, D. J., \& Fletcher, D. (2017). Effects of psychological and psychosocial interventions on sport performance: a meta-analysis. Sports Med. 47, 77-99. $\underline{10.1007 / \mathrm{s} 40279-016-0552-7}$
33. Haneishi, K., Fry, A. C., Moore, C. A., Schilling, B. K., Li, Y., \& Fry, M. D. (2007). Cortisol and stress responses during a game and practice in female collegiate soccer players, 21(2), 583-88. 10.1519/R-20496.1

34. Turner, M. J., Slater, M. J., \& Barker, J. B. (2014). Not the end of the world: The effects of rational-emotive behavior therapy (REBT) on irrational beliefs in elite soccer academy athletes. Journal of Applied Sport Psychology, 26(2), 144-156. 10.1080/10413200.2013.812159

35. Murphy, S. M., \& Jowdy, D.P. (1993). Imagery and mental practice. In T.S.Horn (Ed.), Advances in sport psychology (pp.221- 250). Champaign, IL: Human Kinetics. 10.1080/10413200209339007

36. Sofian, O.F., \& Abdullah, R. (2009). The Effectiveness of Imagery and Coping Strategies in Sport Performance. Eur J Soc Sci, 1(9), 97-108.

37. Lau, M. A., \& McMain, S. F. (2005). Integrating mindfulness meditation with cognitive and behavioural therapies: The challenge of combining acceptance-and change-based strategies. The Canadian Journal of Psychiatry, 50(13), 863-869. $10.1177 / 070674370505001310$

38. Theodorakis, Y., Hatzigeorgiadis, A., \& Chroni, S. (2008). Self-talk: It works, but how? Development and preliminary validation of the functions of self-talk questionnaire. Measurement in Physical Education and Exercise Sciences, 12, 10-30. 10.1080/10913670701715158

39. Mills, K. D., Munroe, K. J., \& Hall, C. R. (2000). The relationship between imagery and selfefficacy in competitive athletes. Imagination, Cognition and Personality, 20(1), 33-39. 10.2190/FC65-AP4T-E94J-5W7P

40. Walter, N., Nikoleizig, L., \& Alfermann, D. (2019). Effects of Self-Talk Training on Competitive Anxiety,Self-Efficacy, Volitional Skills, and Performance:An Intervention Study with Junior SubElite Athletes. Sports (Basel), 7(6), 148-167. 10.3390/sports 7060148

41. Kasala, E. R., Bodduluru, L. N., Maneti, Y., \& Thipparaboina, R. (2014). Effect of meditation on neurophysiological changes in stress mediated depression. Complementary therapies in clinical practice, 20(1), 74-80. 10.1016/j.ctcp.2013.10.001

42. Shapiro, S. L., Schwartz, G. E., \& Bonner, G . (1998). Effects of Mindfulness-Based Stress Reduction on Medical and Premedical Students. 


\section{Pre-competitive stress in elite shooters}

Journal of Behavioral Medicine, 21, 581-599. 10.1023/A:1018700829825

43. Williams, K. A., Kolar, M. M., Reger, B. E., \& Pearson, J. C. (2001). Evaluation of a wellnessbased mindfulness stress reduction intervention: A controlled trial. American Journal of Health Promotion, 15(6), 422-432. 10.4278/0890-117115.6 .422

44. Lazar, S. W., Keer, C. E., Wasserman, R. H., Gray, J. R., Greve, D. N., Treadway, M. T., et al. (2005). Meditation experience is associated with increased cortical thickness. Aging, 16(17), 1893-97. 10.1097/01.wnr.0000186598.66243.19

45. Creswell, J. D., Way, B. M., Eisenberger, N. I., \& Lieberman, M. D. (2007). Neural correlates of dispositional mindfulness during affect labeling. Psychosomatic Medicine, 69, 560-565. 10.1097/PSY.0b013e3180f6171f

46. Pepping, C. A., Donovan, A. O., \& Davis, P. J. (2013). The positive effects of mindfulness on selfesteem. Journal of Positive Psychology, 8(5), 376386. 10.1080/17439760.2013.807353

47. Josefsson, T., Ivarsson, A., Lindwall, M., Gustafsson, H., Stenling, A., Böröy, J., Mattsson, E., Carnebratt, J., Sevholt, S., \& Falkevik, E. (2017).
Mindfulness mechanisms in sports: mediating effects of rumination and emotion regulation on sport-specific coping. Mindfulness, 8(5), 1354-1363. 10.1007/s12671-017-0711-4

48. Bara, F. G., Ribeiro, L.S., Miranda, R., \& Teixeira, M. T. (2002). Reduction of blood cortisol levels through the progressive relaxation technique in swimmers. Rev Bras Med Esporte, 8(4), 139-143. 10.1590/S1517-86922002000400002 